\title{
ANÁLISE DE ÁREAS DE VULNERABILIDADE HÍDRICA NA BACIA HIDROGRÁFICA DE PEDRAS/PITUAÇU ATRAVÉS DE SIG
}

\section{VULNERABILITY ANALYSIS OF AREAS IN WATER BASIN OF PEDRAS / PITUAÇU THROUGH GIS}

\author{
Luciana Santiago Rocha \\ Universidade Federal da Bahia \\ lurocha.geo@hotmail.com \\ Vivian de Oliveira Fernandes \\ Universidade Federal da Bahia \\ vivian.deofernandes@gmail.com
}

\begin{abstract}
RESUMO
Os espaços urbanos apresentam carências no planejamento e no controle da ocupação do solo que tem acentuado ou criado áreas de vulnerabilidade hídrica como aquelas sujeitas a alagamentos. O objetivo deste trabalho foi analisar e mapear essas áreas através de dados referentes às notícias de alagamentos divulgadas pelo jornal A Tarde e de dados obtidos junto à Comissão de Defesa Civil do Salvador (Codesal). Por meio do SIG eles foram associados ao MDT, à declividade e a impermeabilização da área. Para aplicação do método proposto, foi adotada a bacia hidrográfica de Pedras/Pituaçu situada em Salvador-Bahia. Os resultados obtidos indicaram que não há coincidência entre os locais com ocorrências de alagamentos identificados pelos dados do A Tarde e da Codesal, e que, a forma de registros de ocorrências desse último órgão está aquém das necessidades para a realização de análises espaciais e identificação de áreas que necessitam de intervenção. Através desse indicativo pôde-se apontar a informação espacial como elemento relevante para o planejamento e gestão das áreas de vulnerabilidade hídrica.
\end{abstract}

Palavras-chave: espaço urbano, bacia hidrográfica, vulnerabilidade hídrica e sistema de informações geográficas.

\footnotetext{
ABSTRACT

Urban spaces present shortcomings in the planning and control of land use that has created or enhanced areas of water vulnerability as those subject to flooding. The aim of this study was to analyze and map these areas through data referring to the news released by flooding the newspaper A Tarde and data obtained from the Civil Defense (Codesal ). Through the GIS they were associated with the MDT, the slope and waterproofing the area. For applying the proposed method, we adopted the watershed Pedras / Pituaçu located in Salvador in Bahia state. The results indicated that there is no coincidence between the sites with occurrences of flooding identified by data from The 
Evening and Codesal, and that the form of records of occurrences of the latter body is short of the requirements for performing spatial analysis and identification of areas that need intervention. Through this indication could be pointed to as a factor relevant spatial information for planning and management in the areas of water vulnerability .

Keywords: urban space, watershed vulnerability hydro and geographic information system.

\section{INTRODUÇÃO}

Centro de moradia de grande parte da população mundial, os espaços urbanos apresentam carências no seu planejamento e no controle da ocupação do solo, que associados à implantação de infraestrutura inadequada, tem levado os ambientes naturais a uma degradação contínua e, por vezes, acentuado ou mesmo criado áreas de vulnerabilidade hídrica.

Com o desenvolvimento urbano, a cobertura vegetal foi substituída por pavimentos e materiais impermeáveis presentes em telhados, calçadas, ruas asfaltadas e lajes. Esse conjunto de elementos altera significativamente o ciclo hidrológico natural e levam às seguintes mudanças nesse ciclo: redução da infiltração, do escoamento subterrâneo e da evapotranspiração da água, e aumento do seu escoamento superficial o que vai favorecer a ocorrência de alagamentos.

Aliadas às questões mencionadas, as obras e projetos de infraestrutura urbana inadequada; a disposição irregular dos resíduos sólidos e a interferência física no sistema de drenagem natural (por meio de obras de canalização fechada de rios) têm contribuído de forma decisiva para a ampliação dos impactos ambientais urbanos como os alagamentos. Esses eventos tornaram-se um problema bastante recorrente no cotidiano das famílias brasileiras, pois atacam à integridade urbana, sendo percebidos pelos transtornos na circulação de transportes, na comunicação, nas atividades e nos serviços, pelos problemas sanitários, pelas perdas e danos econômicos e sociais, dentre outros.

Nesse contexto, este artigo apresenta a aplicação do Sistema de Informação Geográfica na análise de áreas de vulnerabilidade hídrica na Bacia Hidrográfica de Pedras/Pituaçu, localizada no município de Salvador na Bahia. Esta bacia foi escolhida após prévia análise que revelou nesta região uma das áreas críticas do município e com 
grande quantidade de registros de alagamentos. Além disso, entende-se que a bacia hidrográfica é uma importante unidade de análise que foi adotada nas diretrizes da Política Nacional de Proteção e Defesa Civil - PNPDEC (Lei 12.608/2012) como unidade para ações de prevenções de desastres relacionados a eventos hídricos.

\section{AMBIENTE URBANO}

Com a urbanização o ser humano transformou ambientes naturais criando outros, em uma complexa teia de obras para atender todas as suas necessidades como ser social. Dessa forma, a cidade pode ser compreendida como produto da interação entre as dimensões sociais e naturais. Segundo Mendonça (2001), o estudo da cidade sob um ponto de vista mais holístico é recente e pode ser representado de acordo com o esquema na Figura 1.

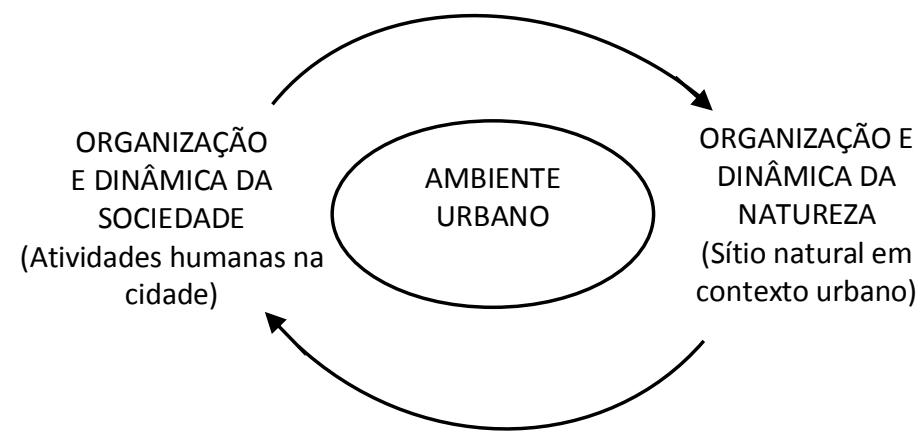

Figura 1. Esquema genérico do estudo do ambiente urbano Fonte: Adaptado de Mendonça (2001)

É preciso estudar a cidade sob uma perspectiva que rompa com a clássica visão resultante da forma positivista de separação dos campos do conhecimento (MENDONÇA, 2004). Assim, a abordagem integrada entre natureza e sociedade é imprescindível já que este espaço é produto da inter-relação entre esses agentes.

Moreira (1999) realizou um trabalho onde discute as definições de ambiente urbano a partir de diferentes perspectivas e, por fim, com base na contribuição de biólogos, paisagistas e urbanistas, o conceitua como relação do homem com o espaço construído e com a natureza, marcado por aglomerações de população e atividades humanas e pela apropriação e fruição (utilização e ocupação) do espaço construído e dos recursos naturais. 
Para Braga e Carvalho (2003), o "meio ambiente urbano" refere-se, ao ambiente natural que foi transformado e vem desaparecendo das cidades "sobrepujado pelas formas concretas de ocupação do território (rios canalizados, solo impermeabilizado, etc.)".

Baseado em diversos trabalhos e tendo como base a perspectiva sistêmica, Mendonça (2004) lança uma proposta denominada Sistema Ambiental Urbano (S.A.U.) (Figura 2), onde constam três subsistemas: o natural, o construído e o social. Os primeiros representam o input do S.A.U. e o último oferece a dinâmica através das relações humanas. Os problemas socioambientais urbanos aparecem como o output, ou seja, os resultados dessa integração que, por sua vez, devem ser administrados com propostas para sua solução.

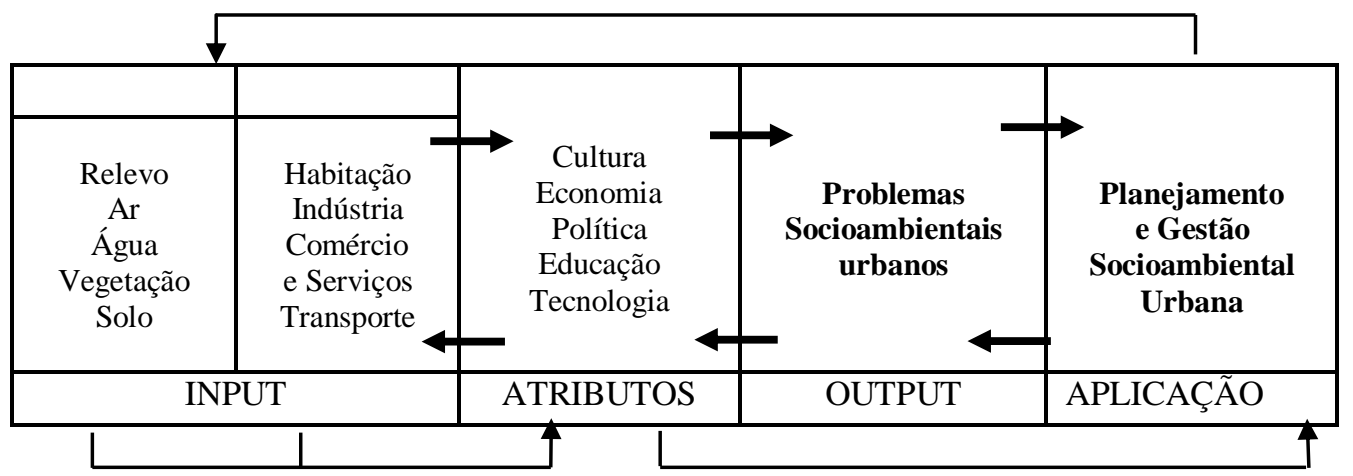

Figura 2. S.A.U. - Sistema Ambiental Urbana (SIMPLIFICADO)

Fonte: Adaptado de Mendonça (2004)

O sistema ambiental urbano tem características e funcionamento diferentes dos outros sistemas ecológicos, pois nele a ação do homem é predominante, provocando mudanças intensas e rápidas. Compete ao homem procurar adequar o processo de urbanização às características do ambiente, de modo que seus efeitos negativos sejam mínimos. A intensificação das preocupações com o ambiente urbano deve ser cada vez mais crescente e demandam o aprofundamento das reflexões acerca da abordagem interdisciplinar, bem como, para a proposição de ações visando à melhoria da gestão ambiental urbana.

\section{VULNERABILIDADE HÍDRICA}


O conceito de vulnerabilidade abrange distintos fatores e processos que refletem a susceptibilidade, a predisposição e as condições que favorecem ou facilitam que aconteça uma perda ou desastre frente a uma ameaça. Ela varia de acordo com o tempo, a localização geográfica, as condições sociais, econômicas, infraestruturais e ambientais de cada lugar.

Esse termo tem sido definido por distintos autores a partir de diferentes acepções e seu significado não é consenso em estudos sobre o tema o que dificulta a comparação dos resultados de trabalhos semelhantes. Cutter (1996, apud Hogan et al.) realizou uma revisão do termo e propôs a seguinte categorização: vulnerabilidade como condição pré-existente, vulnerabilidade como resposta moderada e vulnerabilidade como risco do lugar. Esta última é a que mais se aproxima do entendimento adotado neste trabalho.

Para Marandola Jr. e Hogan (2005), entender o termo vulnerabilidade nas diversas abordagens científicas é algo que não pode ser realizado sem considerar, ao mesmo tempo, o conceito de risco. Segundo estes autores, zonas perigosas referem-se a áreas costeiras, zonas sísmicas, planícies inundáveis com grau de perdas (de vida e propriedade) associado à ocorrência de um evento particular (inundação, furacão, terremoto).

De acordo com Santos (2007), o meio torna-se vulnerável quando uma mudança ocorrida nele provoca também uma modificação na configuração espacial da paisagem. Isto significa dizer que há uma resposta do próprio meio para cada alteração sofrida, podendo ocorrer um rearranjo destes mesmos componentes, resultando em uma situação diferente da anterior.

Sobre a vulnerabilidade hídrica é possível afirmar que ela caracteriza-se como uma das mais típicas no Brasil e na cidade do Salvador, estando associada a locais sujeitos a alagamentos, inundações e enxurradas. Nesses locais os eventos hídricos mencionados, acabam gerando grandes prejuízos, pois fatores como a impermeabilização, a disposição inadequada de lixo e a ocupação urbana em áreas inadequadas, acabam dificultando o escoamento superficial da água.

\section{SISTEMAS DE INFORMAÇÕES GEOGRÁFICAS}


Os sistemas de informações são utilizados para manipular, sintetizar, editar e visualizar informações, geralmente armazenadas em bases de dados computacionais. Os sistemas de informações geográficas (SIG) utilizam informações espaciais sobre o que está/ou ocorre na superfície da Terra, ou seja, é um poderoso conjunto de ferramentas para coleta, armazenamento e recuperação de dados espaciais do mundo real (BURROUGH, P. A. e MCDONNELL, R. A., 1998).

Para Pereira e Silva (2001), os SIGs podem ser considerados como modelos de sistemas do mundo real e além de serem modelos que cumprem "as funções dos modelos convencionais (mapas, maquetes), acrescentam novos horizontes às atividades de análise, planejamento, projeto e gestão". Segundo esses mesmos autores, o SIG aplicado em estudos urbanos apresenta as vantagens de visualização, organização de dados e modelagem espacial. A visualização é feita, normalmente, sobre mapas e oferece rápidas respostas para mudanças nos padrões cartográficos. A visualização possibilita expor tendências e relações que nem sempre são percebidas numa análise inicial, como, por exemplo, registros cartográficos do acontecimento de acidentes de trânsito indicam a localização de pontos de conflito de tráfego, ou interseção de vias que precisam de uma intervenção efetiva. Nestes casos, a visualização é um instrumento efetivo que permite definir planos ou projetos específicos.

$\mathrm{Na}$ organização de dados, a vantagem do SIG provém do referenciamento espacial desses dados. Um SIG pode ser pensado como um sistema gerenciador de base de dados, desenhado especificamente para suportar a armazenagem eficiente e a recuperação de dados espaciais. Por fim, como vantagem para a modelagem, o SIG oferece várias técnicas de modelagem que permitem modelar percepções bastante complexas da realidade.

Quanto à aplicação de SIG em análises ambientais, Silva e Zaidan (2004) afirmam que ele é ideal para essas análises, pois é ao mesmo tempo instrumento conceitual, metodológico e tecnológico que respeita e integra em si próprio, algumas características fundamentais dos dados ambientais, como:

a) os dados ambientais são extremamente numerosos o que impõe o uso do processamento de dados no seu tratamento;

b) estes dados são de tipos variados e vêm de muitas fontes;

c) os dados ambientais impõem o trabalho multi e interdisciplinar; 
d) os dados ambientais têm, por definição, uma localização geográfica e, consequentemente, podem ser geocodificados.

\section{MATERIAIS E MÉTODO}

O estudo foi desenvolvido na bacia hidrográfica de Pedras/Pituaçu localizada na área urbana do município de Salvador-BA, com uma área de 27,05 km², correspondente a $8,76 \%$ do território municipal (Figura 3). Essa é a quarta maior bacia hidrográfica de Salvador, em termos de superfície e, a terceira mais populosa com 275.781 habitantes e densidade populacional de 10.194,31 hab./km² (SANTOS et al., 2010), possuindo notável importância ecológica, histórica e cultural.

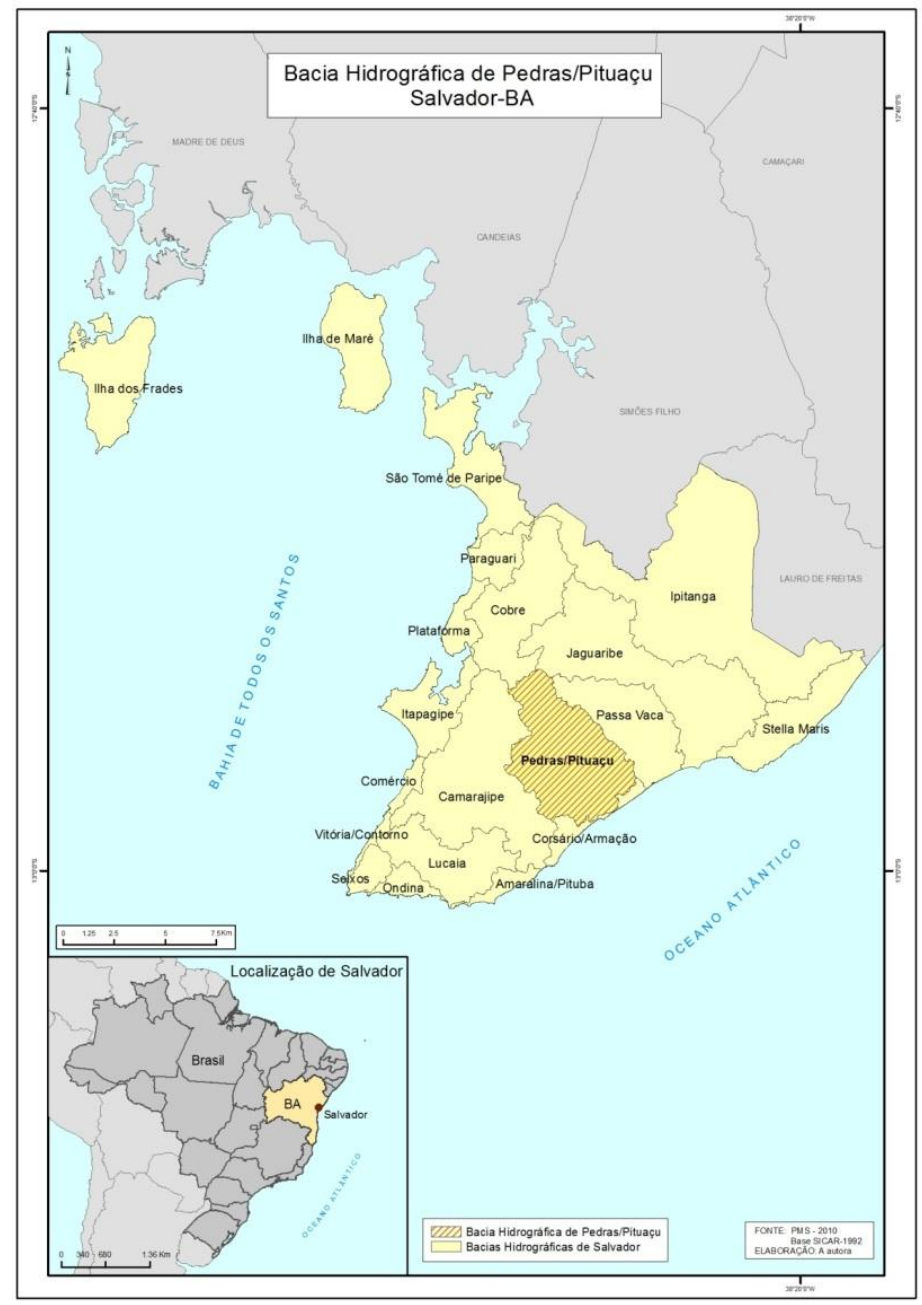

Figura 3. Localização da Bacia Hidrográfica de Pedras/Pituaçu na cidade do Salvador-BA 
Os materiais utilizados foram as bases cartográficas do Sistema Cartográfico da Região Metropolitana de Salvador (SICAR/RMS) do ano de 1992 e do Sistema Cartográfico e Cadastral do Município do Salvador (SICAD/PMS) de 2006, ambas na escala 1:2.000, projeção Universal Transversa de Mercator (UTM), datum planimétrico SAD 69 e datum altimétrico em Imbituba-SC.

Como dados alfanuméricos, foram utilizados registros de alagamentos encontrados no site do jornal A Tarde, dos anos de 1997 a 2010. A adoção desse período deve-se ao fato deste ser o período disponibilizado pelo referido meio de comunicação para consultas de notícias em meio digital e on line, o que facilitou acesso aos tais dados. Este jornal foi escolhido, dentre outros da mídia local, por ser um dos mais antigos e de maior circulação em Salvador e região, e por possuir credibilidade entre a população.

Os outros dados utilizados também foram secundários e fornecidos pela Codesal, cujas ocorrências são registradas após denúncia/reclamação dos habitantes e validadas após vistoria de um técnico do órgão. Elas referem-se aos anos de 2006 a 2010, estavam em tabelas organizadas em planilhas e continham os seguintes campos: data / endereço / bairro, conforme exemplo no Quadro $1^{1}$.

Quadro 1. Demonstração do arquivo fornecido pela Codesal com os registros de alagamentos

\begin{tabular}{|c|c|c|}
\hline Data & Endereço & Bairro \\
\hline $\mathbf{0 7 / 0 3 / 2 0 1 0}$ & $1^{\text {a }}$ Travessa Emiliano Galiza, $n^{\circ} 12 \mathrm{C}$ & Boca do Rio \\
\hline $\mathbf{1 3 / 0 6 / 2 0 0 6}$ & $3^{\text {a }}$ Travessa Canambi, $\mathrm{n}^{\mathbf{o}} 362$ & Boca do Rio \\
\hline $\mathbf{2 8 / 0 4 / 2 0 0 6}$ & $3^{\text {a }}$ Travessa Canambi, $\mathrm{n}^{\mathbf{o}} 51$ & Boca do Rio \\
\hline $\mathbf{2 1 / 0 4 / 2 0 0 6}$ & $3^{\text {a }}$ Travessa Novo Paraíso, $\mathrm{n}^{\mathbf{o}} 325$ & Boca do Rio \\
\hline $\mathbf{2 1 / 0 4 / 2 0 0 6}$ & $3^{\text {a }}$ Travessa Novo Paraíso, $\mathrm{n}^{\mathbf{0}} 325 \mathrm{C}$ & Boca do Rio \\
\hline $\mathbf{2 0 / 0 4 / 2 0 0 6}$ & $3^{\text {a }}$ Travessa Novo Paraíso, $\mathrm{n}^{\mathbf{o}} 327$ & Boca do Rio \\
\hline
\end{tabular}

Fonte: Codesal (2011)

\footnotetext{
1 A tabela completa possui 2.176 campos de registros de ocorrências de alagamentos e por isso não foi colocada na íntegra no artigo.
} 
Para utilizar esses dados foi necessário obter suas coordenadas geográficas e dessa forma, transformou-se essa base de dados em dados espaciais. Tal estratégia foi desenvolvida com a finalidade de integrar as informações de alagamentos (dados pontuais) a um SIG.

Além desses dados, foram utilizadas imagens de satélite do sensor QuickBird, do ano de 2009, com resolução espacial de 0,65m, no sistema de referência WGS-84 e na projeção UTM.

Como programas computacionais foram usados o Excel para a organização dos dados tabulares, o ArcGis 10 para o processamento dos dados alfanuméricos, bem como, para aplicação das técnicas de análise espacial e geração dos mapas temáticos e, o ENVI 4.7 para o pré-processamento das imagens QuickBird e como auxílio para a classificação e análise dessas.

Também foram realizadas entrevistas aos técnicos dos setores de Comunicação e Informática e da Ouvidoria e Vistoria da Codesal, com o intuito de conhecer a forma de levantamento e registro das ocorrências de alagamento.

\section{RESULTADOS E DISCUSSÕES}

Com o desenvolvimento dos procedimentos estabelecidos, um dos resultados alcançados foi à distribuição espacial dos alagamentos obtidos através do levantamento dos dados do Jornal A Tarde que abrangiam todo o município e está representado no mapa da Figura 4. 


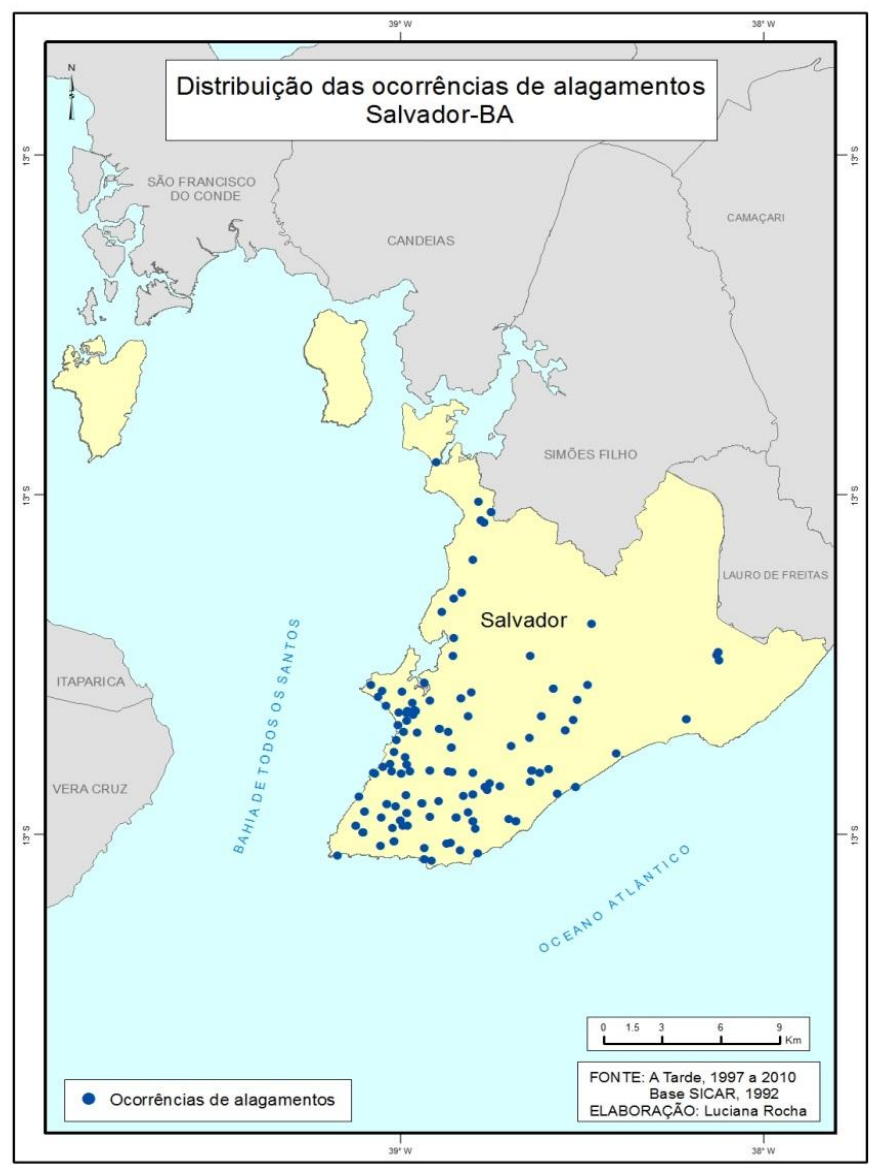

Figura 4. Distribuição espacial das ocorrências de alagamentos divulgadas pelo A Tarde

Seguidamente, para se conhecer os pontos críticos no município, foi aplicado nesse conjunto de dados um método de análise espacial: o estimador de intensidade Kernel, que realiza uma contagem dos dados pontuais dentro de uma região de influência ponderando-os pela distância de cada um à localização de interesse determinando, por fim, a concentração de um evento em determinada área. Para a aplicação do Kernel foi usado o programa ArcGis 10 e como parâmetros para a estimação do raio de influência foi adotado o valor de 500 metros, escolhido após verificações das distâncias médias entre os pontos de ocorrências de alagamentos.

Os resultados do método Kernel, expressos no mapa na Figura 5, demonstram que as ocorrências de alagamentos ao longo dos 13 anos considerados, apresentam uma concentração irregular no espaço geográfico de Salvador e a estimação das áreas com maior intensidade, revelaram quatro áreas críticas no município. 


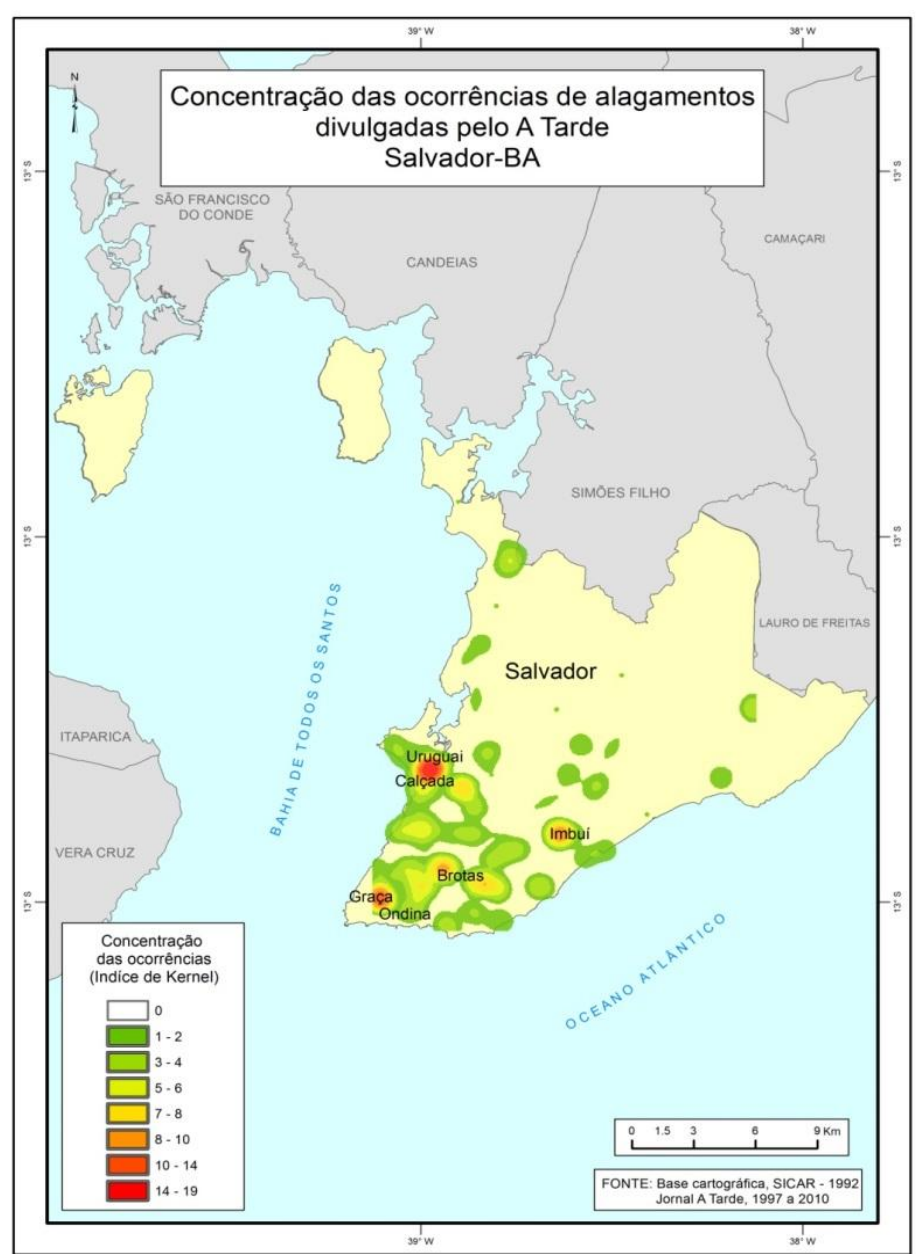

Figura 5. Concentração das ocorrências de alagamentos divulgadas pelo Jornal A Tarde no município de Salvador de 1997 a 2010

Por meio desse resultado, foi escolhida uma das quatro áreas críticas, ou seja, onde está situado o bairro do Imbuí, para o aprofundamento das análises. Como esse bairro está inserido na bacia hidrográfica de Pedras/Pituaçu, ela foi adotada como unidade de estudo.

A partir da definição dessa bacia, os dados avaliados da Codesal foram apenas os referentes aos bairros contidos nessa unidade e, por meio do processamento das 587 ocorrências nessa bacia, obteve-se a distribuição espacial apresentada no mapa a seguir (Figura 6). 


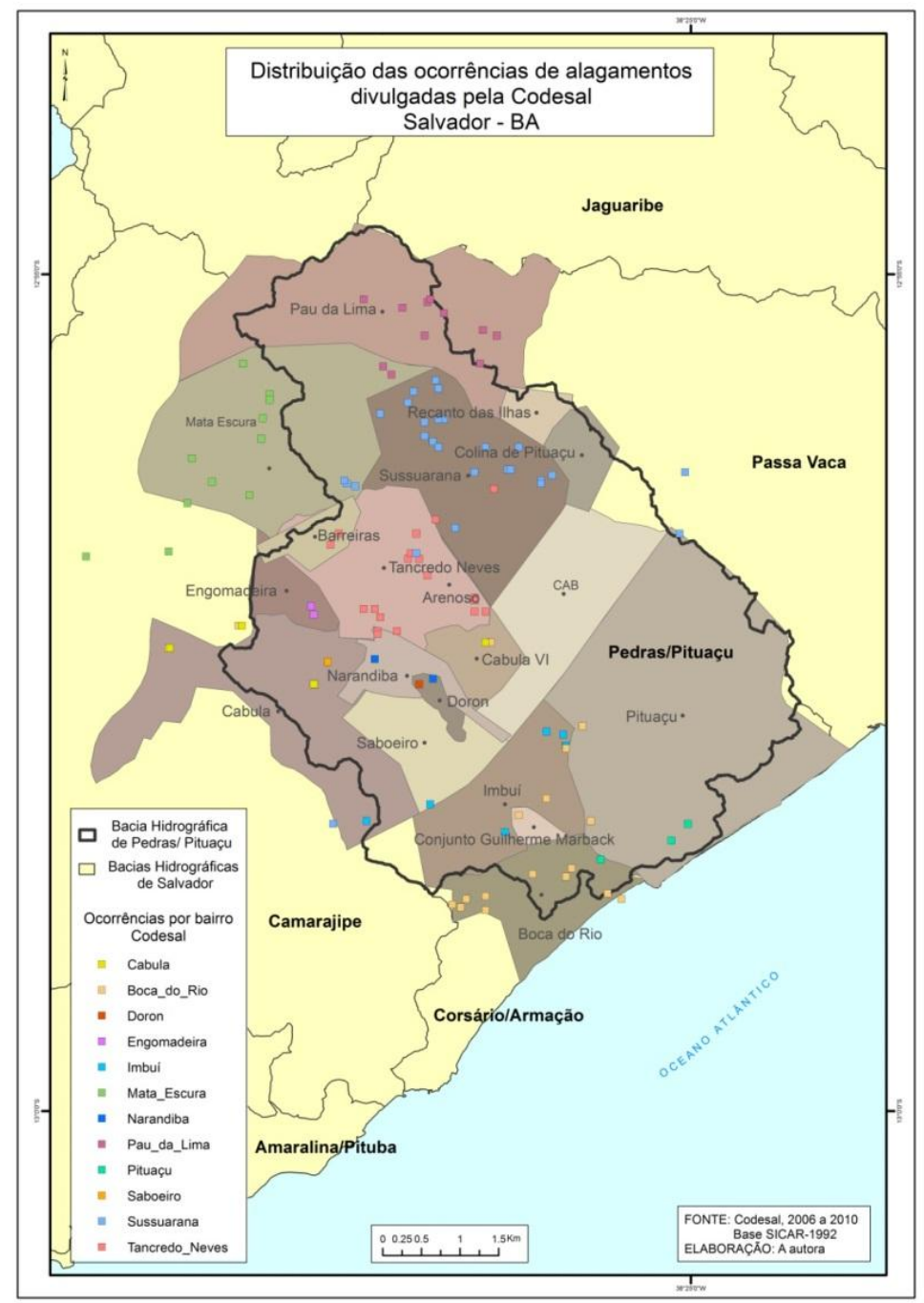

Figura 6. Distribuição das ocorrências de alagamentos divulgadas pela Codesal

A análise dessas ocorrências revelou que a Codesal não considera as dimensões dos bairros quando valida um registro. Dois bairros em especial: Mata Escura e Sussuarana apresentaram casos muito distantes dos seus limites territoriais e nesse segundo bairro houve um logradouro registrado no seu banco que oficialmente pertence a outro bairro, que nem sequer faz limite com ele. Outro caso que despertou atenção foi que todas as ocorrências do bairro do Cabula, se sobrepuseram às ocorrências da Boca do Rio porque, ora o logradouro foi definido como sendo de um bairro ora como de outro. Constatou-se ainda outros erros como, por exemplo, a Rua da Bolandeira, que de acordo com o cadastro de logradouros da prefeitura municipal está no bairro de Pituaçu, encontra-se registrada no banco da Codesal ora como pertencente ao bairro de Pituaçu, ora como Boca do Rio e em outras situações como do Imbuí. 
A avaliação desses dados, de forma isolada e sem associação a outros bancos e/ou fatores, demonstraram que eles possuem problemas tanto na forma com que se registra a ocorrência, quanto na definição de sua localização, o que caracteriza uma deficiência para a implementação de programas de prevenção que tomem como referência a representação espacial do dado.

Mesmo conscientes das falhas que o registro desses logradouros possui, optouse por realizar a espacialização dos dados da Codesal para identificar os locais mais críticos, com o intuito de apresentar uma das formas e ratificar os benefícios que o correto registro do logradouro pode oferecer. No mapa na Figura 7, as simbologias de tamanho e cor foram adotadas e permitiram a identificação da área mais crítica na bacia: a rua da Bolandeira, que teve mais de 300 registros no período avaliado. Análises semelhantes a esta podem ser feitas pelos técnicos da Codesal e poderão auxiliar na identificação de locais para interferência desse órgão.

Para uma nova etapa das análises, produziu-se o mapa (Figura 8) resultante da sobreposição dos dados do jornal A Tarde e da Codesal. Neste, foi possível observar que não há coincidência entre as áreas de ocorrências de alagamentos divulgadas pela mídia com as registradas pelo órgão da defesa civil.

Outra constatação com a análise dos dados do A Tarde revela que a mídia não tem informado o que a população denuncia junto à defesa civil. Ela divulga os fatos que causam maiores prejuízos à circulação de moradores e veículos, o que pode ser percebido, por exemplo, nos títulos de suas reportagens: "Chuva alaga ruas de Salvador", "Baixa do Fiscal: ruas alagam após 10 minutos de chuva" e "Alagamento afeta trânsito na Calçada".

Com a confirmação, portanto, que os registros de alagamentos divulgados pela mídia não tem relação com os registrados pelo órgão da defesa civil do município, esse dados não foram agregados ao banco e a pesquisa prosseguiu utilizando os dados oficiais da Codesal. 


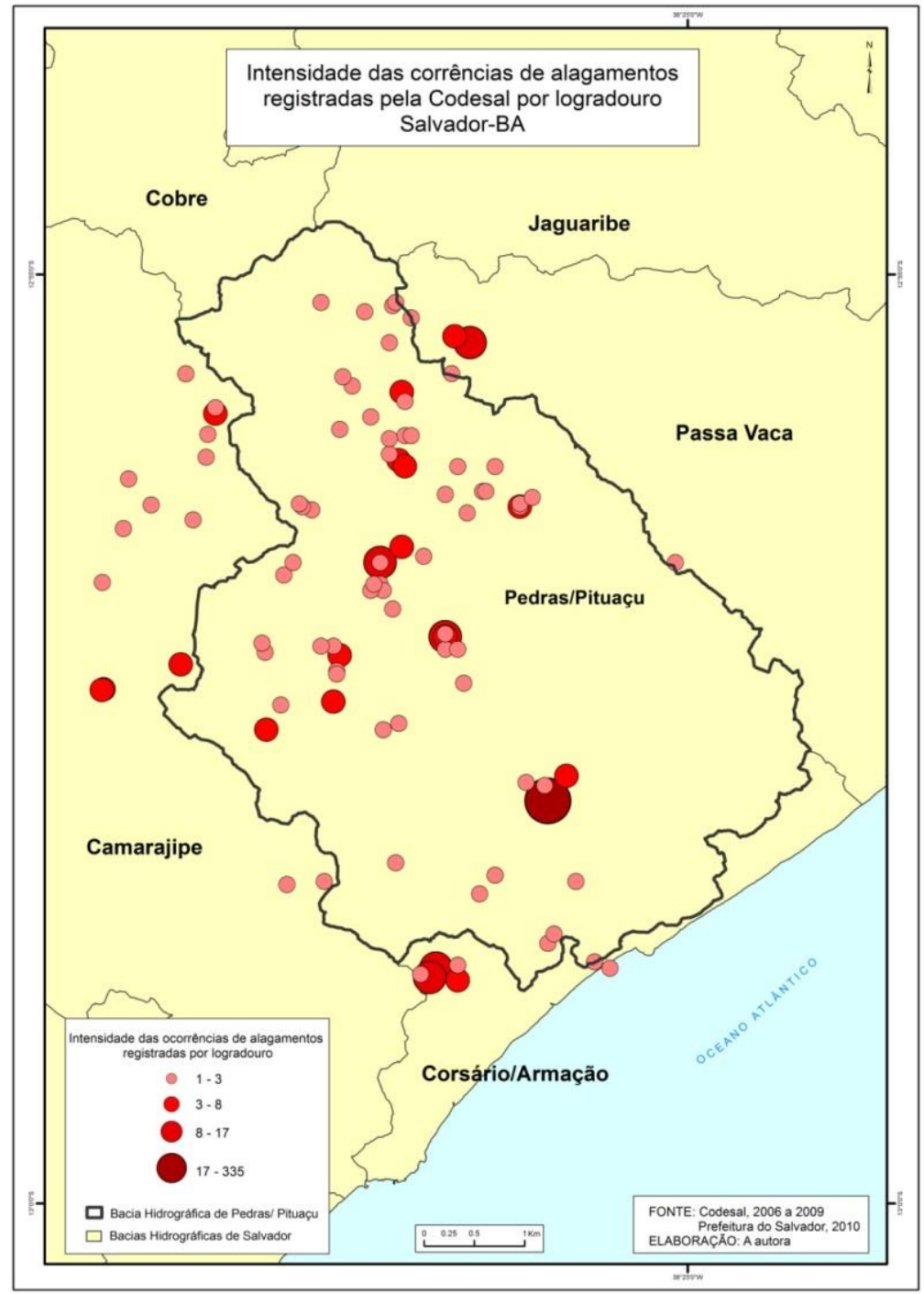

Figura 7. Intensidade das ocorrências de alagamentos registradas pela Codesal por logradouro 


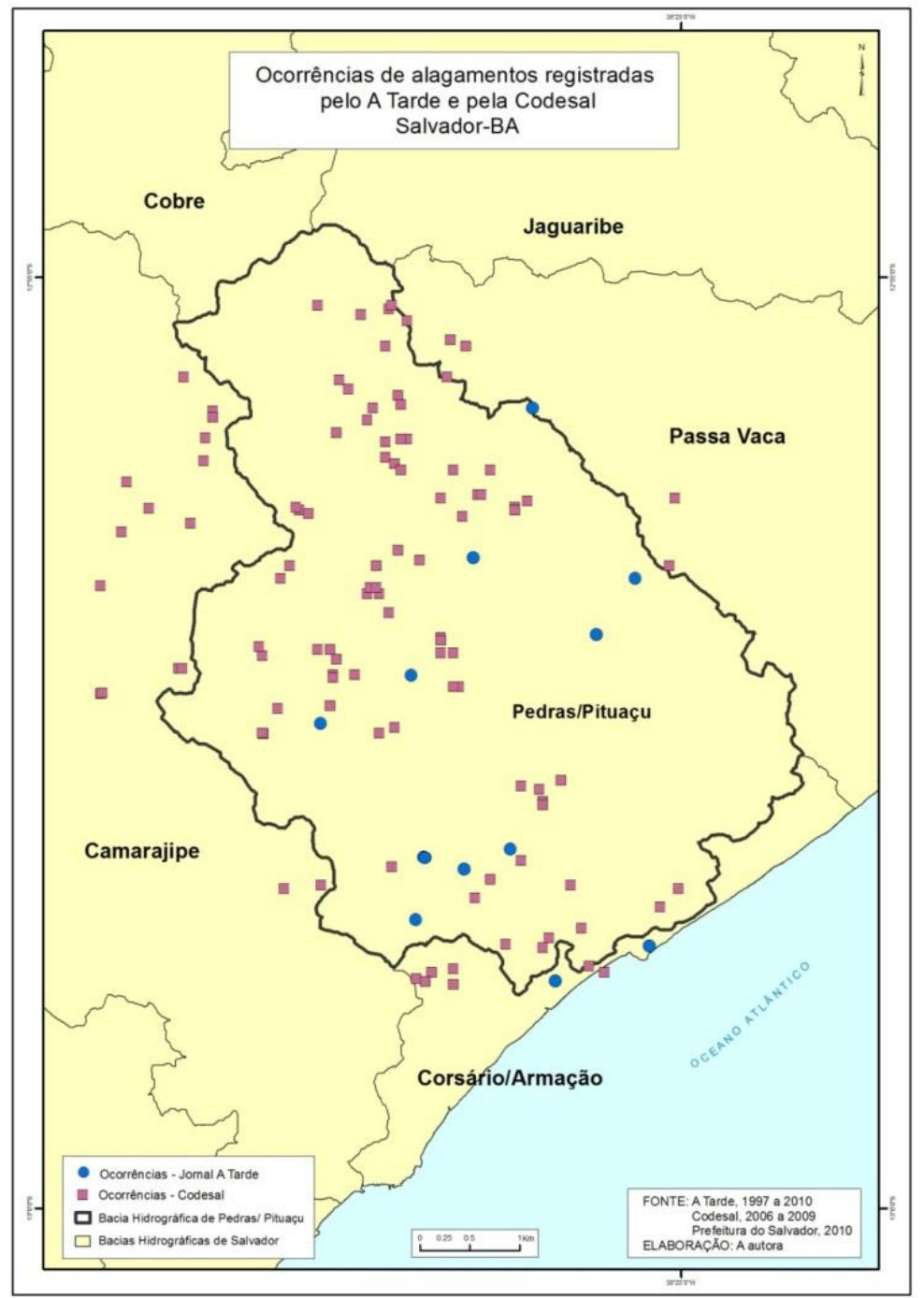

Figura 8. Mapa resultante da sobreposição dos dados do A Tarde e da Codesal

Para nova etapa da pesquisa, o uso de técnicas de sensoriamento remoto e de SIG foram de grande importância, permitindo o tratamento das imagens QuickBirb que, após vetorização e classificação visual, levaram à identificação de cinco usos predominantes na bacia hidrográfica, mapeadas nas seguintes classes: vegetação, solo exposto, nuvem, hidrografia e área construída (Figura 9). 


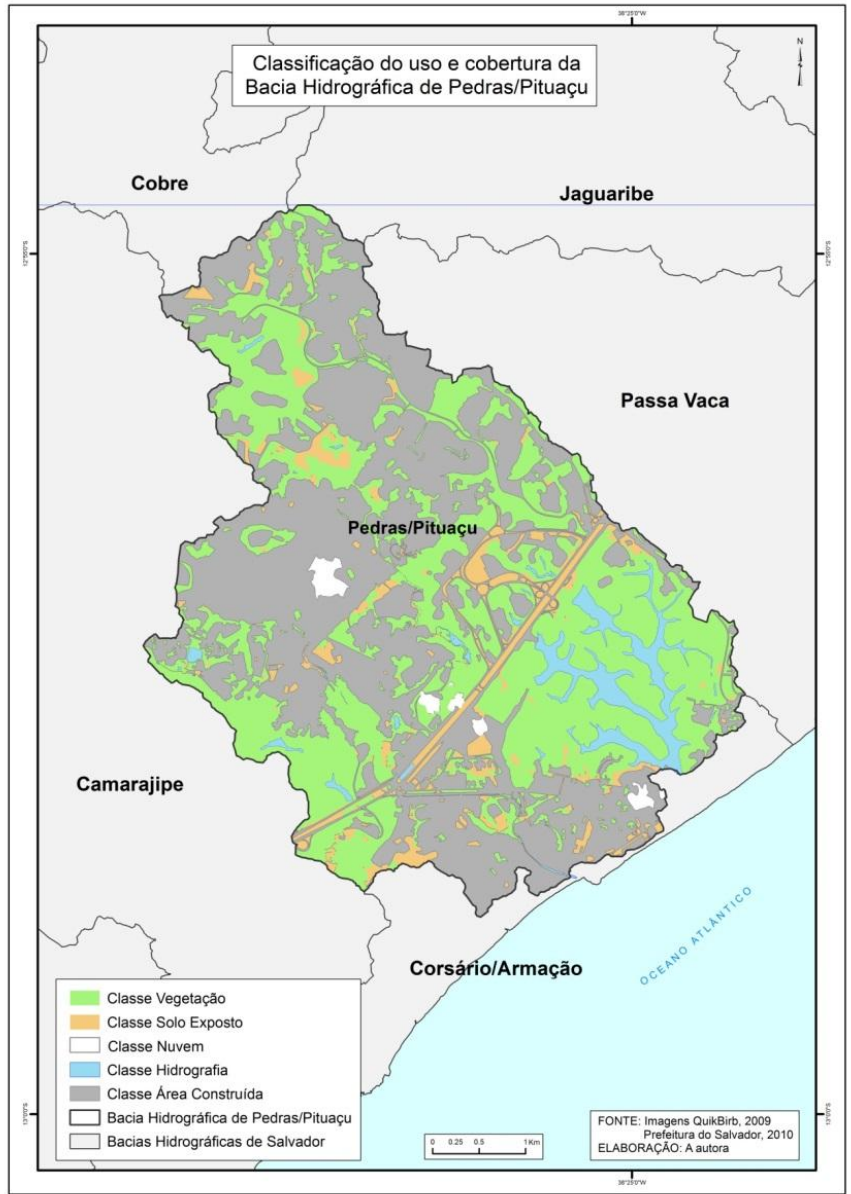

Figura 9. Mapa da classificação das imagens

Para uma avaliação quantitativa, foi levantado o total da área em metros quadrados que cada classe ocupava e, constatou-se que área construída é a predominante e representa mais da metade do uso identificado na imagem. Esses valores obtidos em metros foram convertidos para valores em porcentagem e estão representados na Figura 10.

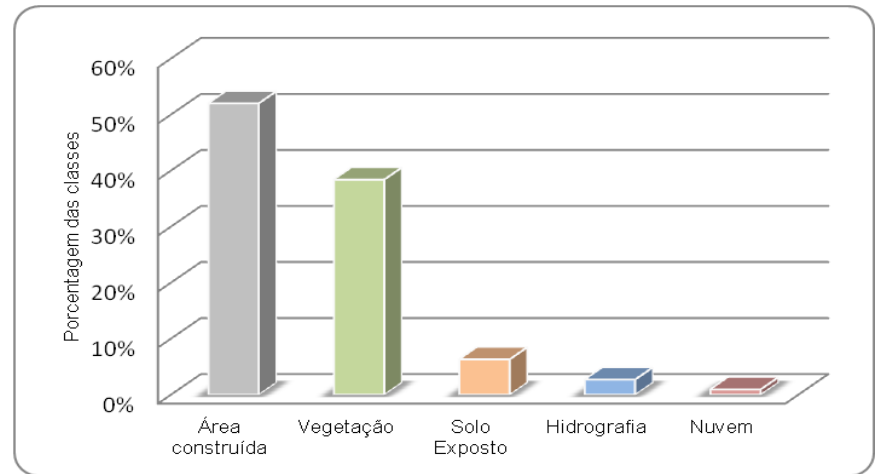

Figura 10. Áreas das classes em porcentagens, obtidas através da análise visual das imagens Quikbird de 2010 
Com o agrupamento dessas classes em três grupos: permeáveis, impermeáveis e outros, obteve-se a classificação de áreas permeáveis e impermeáveis da bacia representadas no mapa da Figura 11. Esse mapa e o gráfico na Figura 12 revelam que grande parte da bacia está na classe impermeável. Esse fator conduz e intensifica a vulnerabilidade hídrica dessa unidade, pois a impermeabilização do solo é um elemento muito importante que deve ser considerado nos estudos de alagamento, visto que influencia significativamente o volume de água escoado superficialmente e a velocidade de seus fluxos.

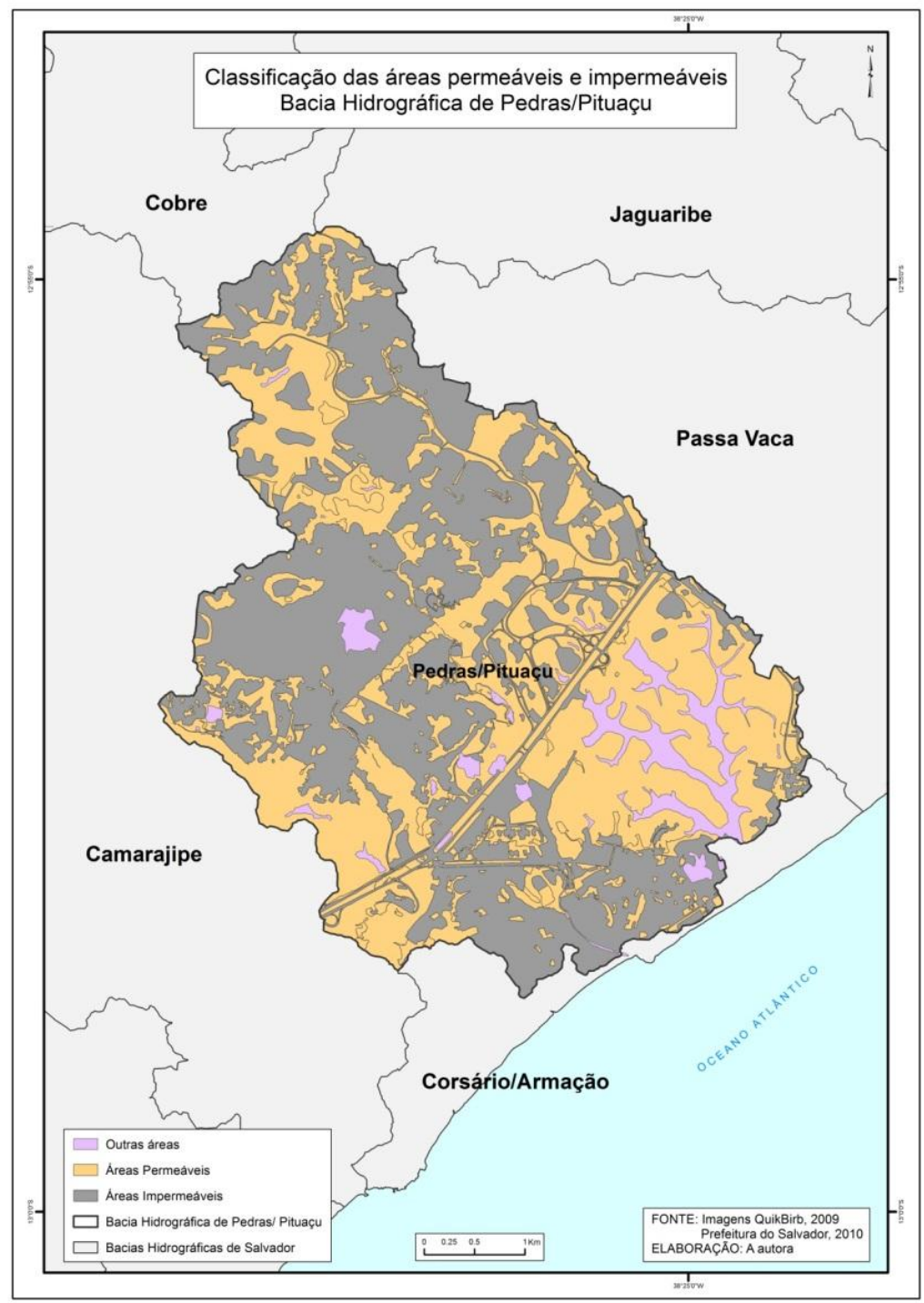

Figura 11. Mapa da classificação das áreas permeáveis e impermeáveis 


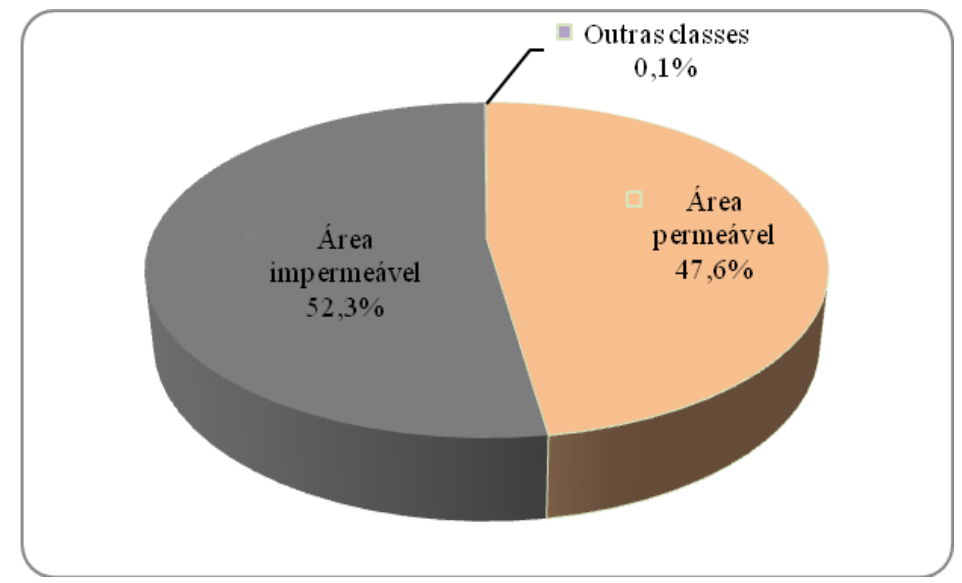

Figura 12. Áreas totais em porcentagem das classes permeável e impermeável, obtidas através da classificação visual das imagens Quikbird de 2010

Dando prosseguimento à metodologia, foram realizadas comparações entre as ocorrências de alagamentos registradas pelo órgão da defesa civil do município com as áreas identificadas como impermeáveis e revelado nessa avaliação (Figura 13) foi que os casos registrados por esse órgão estão concentrados nas áreas impermeáveis. 


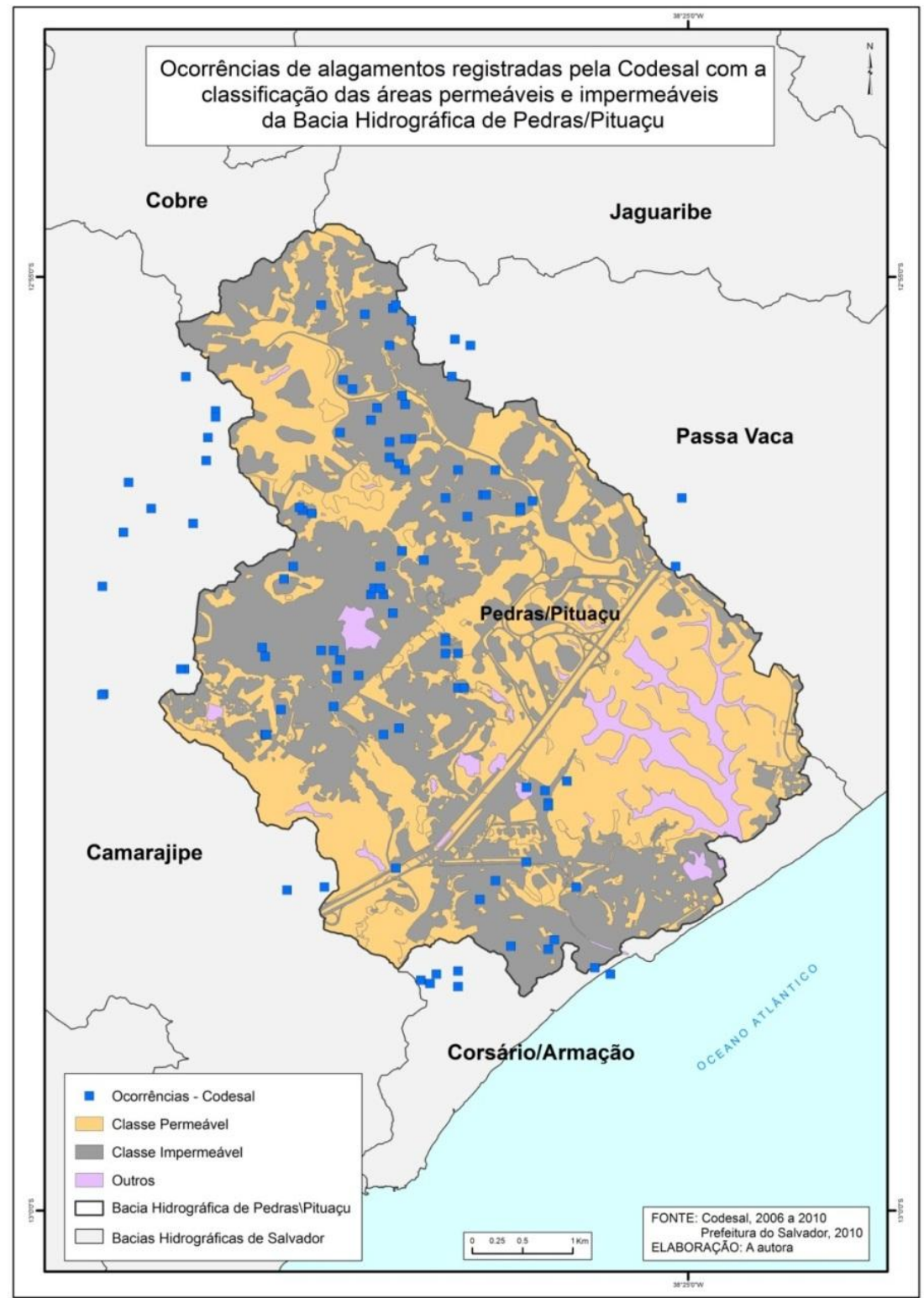

Figura 13. Mapa com ocorrências de alagamentos associadas à classificação de áreas permeáveis e impermeáveis

\section{CONSIDERAÇÕES FINAIS}

A forma como o ambiente urbano é tratado tem determinado o grau de fragilidade desse compartimento frente a eventos e desastres vividos pela população urbana. Percebe-se que ao longo de décadas pouco ou nada mudou na tentativa de tornar 
as cidades menos susceptíveis a áreas de vulnerabilidade hídrica, o que não foi diferente em Salvador na Bahia.

Mesmo considerando algumas inconsistências dos dados disponíveis, concluiuse que os alagamentos causaram e vem causando danos e prejuízos a sociedade soteropolitana. Nesse sentido, o dado espacial e as geotecnologias são importantes instrumentos para os órgãos de planejamento e gestão pública.

Os resultados induzem a afirmar que é possível transformar notícias de jornais e dados da defesa civil em dados espaciais, no entanto, sugere-se especial atenção na montagem da base de dados no que concerne à identificação dos logradouros. Do diagnóstico dos dados da Codesal identificou-se que, ainda que ela realize o cadastro de eventos e desastres em planilhas que permitem análises quantitativas e sua utilização como memória de eventos históricos, existem questões que precisam ser resolvidas de forma a permitir a obtenção de dados confiáveis. Dentre essas, a definição da coordenada geográfica e a utilização do SIG revelaram-se como necessidades relevantes que permitirão além de análises espaciais a indicação de áreas para ações de prevenção e intervenção.

Ressalta-se também que a utilização de eventos georreferenciados para análise e gestão de áreas urbanas, tem se tornado cada vez mais úteis e, neste sentido, a ocorrência de eventos de responsabilidade da defesa civil tem especial apelo para o georreferenciamento, que possibilita uma melhor localização de áreas vulneráveis. O grande desafio das defesas civis, portanto, não é dar conta dos desastres depois que eles já aconteceram, mas preveni-los, já que em muitos locais eles ocorrem anualmente, nos mesmos bairros, nos mesmos logradouros. Então, evidentemente, existem situações que podem ser prevenidas.

Destaca-se ainda que as geotecnologias, por meio de técnicas de análise espacial têm boas respostas para as demandas de gestão urbana possibilitando o mapeamento associado a informações em bancos de dados, imagens de satélite e fotografias aéreas. Mas, é de fundamental importância a constituição de recursos humanos nessa área, para aumentar o controle e melhorar o gerenciamento das ações e propor alternativas tecnológicas para este gerenciamento.

Outra conclusão que é importante e sobre a qual se tem que avançar, é quanto à forma de tratar as áreas de vulnerabilidade hídrica, que não são apenas resultantes de 
fatores naturais e das condições do tempo meteorológico. Na verdade, elas dependem em muitas conjunturas, da forma de ocupação e intervenção urbana sobre o espaço geográfico, pois, os processos cada vez mais comuns de artificialização dos canais fluviais podem acarretar no agravamento dos alagamentos. Nas grandes cidades brasileiras a retificação e canalização de cursos d'água são medidas frequentemente implementadas pelo poder público na busca de se minimizar ou solucionar os impactos desses eventos. Porém, estas medidas podem agravar o problema, já que levam à diminuição do tempo de concentração das águas, ao aumento do volume hídrico que atinge os cursos d'água como resultado das elevadas taxas de impermeabilização, e à redução de trocas hídricas entre os leitos fluviais e as margens. Somando-se a isso, as vias de circulação tornam-se eixos locais de escoamento concentrado das águas, ocasionando transtornos nos centros urbanos.

Dessa forma, o planejamento e a execução de políticas públicas serão tão mais eficientes e eficazes quanto mais adequadas for a "localização" dos problemas a serem resolvidos. Portanto, a inclusão do mapeamento das ocorrências de alagamentos nas práticas administrativas municipais, vai orientar etapas do processo de gestão ambiental urbana, alicerçadas em bases tecnicamente consistentes.

\section{REFERÊNCIAS}

BRAGA, Roberto; CARVALHO, Pompeu Figueiredo de (Orgs.). Recursos hídricos e planejamento urbano e regional. Rio Claro: Laboratório de Planejamento Municipal, Deplan/UNESP/IGCE, 2003.

Ministério das Cidades. Instituto de Pesquisas Tecnológicas. Mapeamento de riscos em encostas e margem de rios. Celso Santos Carvalho, Eduardo Soares de Macedo e Agostinho Tadashi Ogura. (Orgs.). Brasília, 2007.

BURROUGH, P. A. e MCDONNELL, R. A. Principles of Geographical Information Systems. Oxford: Oxford University Press. 1998.

CÂMARA, G. et al. Anatomia de Sistemas de Informação Geográfica. São José dos Campos: INPE. 1996. Disponível em: http://www.dpi.inpe.br/gilberto/livros.html. Acesso em: 08 fev. 2012.

; MONTEIRO, M. A. V.; MEDEIROS, S. J. Introdução à ciência da

geoinformação. São José dos Campos: INPE, 2001. 344p. Disponível 
em:.http://mtcm12.sid.inpe.br/col/sid.inpe.br/sergio/2004/04.22.07.43/doc/paginadeaces so.html. Acesso em: 25 abr. 2012.

HOGAN, Daniel Joseph, et. al. Urbanização e Vulnerabilidade socioambiental: o caso de Campinas. In: HOGAN, Daniel Joseph, et. al. Migração e Ambiente nas Aglomerações Urbanas. Campinas: UNICAMP, 2001. p. 397-418. Disponível em: http://www.nepo.unicamp.br/. Acesso em: 10 set. 2012.

MARANDOLA JR., E. e HOGAN, D. J. Vulnerabilidades e riscos: entre geografia e demografia. Revista Brasileira de Estudos da População, São Paulo, v. 22, n. 1, p. 2953, jan./jun. 2005.

MENDONÇA, Francisco de A. Abordagem interdisciplinar da problemática ambiental urbano-metropolitana: esboço metodológico da experiência do doutorado em MA\&D da UFPR sobre a RMC - Região Metropolitana de Curitiba. Revista de Meio Ambiente e Desenvolvimento - Cidade e Ambiente Urbano, Curitiba, n.3, p.79-95, jan./jun. 2001. Disponível em: http://www.ojs.c3sl.ufpr.br/ojs2/index.php/made/article/download/3030/2421. Acesso em: 05 mar. 2012.

Sistema Ambiental Urbano: uma abordagem dos problemas socioambientais da cidade. In: MENDONÇA, Francisco de Assis (Org.). Impactos socioambientais urbanos. Curitiba: Ed. UFPR, 2004, p.185-207.

MOREIRA, Antônio Cláudio M. L. Conceitos de ambiente e de impacto ambiental aplicáveis ao meio urbano. Disponível em: http://lproweb.procempa.com.br/pmpa/prefpoa/spm/usu_doc/moreira6onceito impacto urbano.pdf. Acesso em: 05 mar. 2012.

MOTA, Suetônio. Urbanização e meio ambiente. Rio de Janeiro: ABES, 1999.

PEREIRA, Gilberto Corso; SILVA, Barbara Christine Nentwig. Geoprocessamento e Urbanismo. In: GERARDI, Lucia Helena de Oliveira; MENDES, Iandara Alves. (Org.). Teoria, Técnicas, Espaços e Atividades: temas de Geografia contemporânea. Rio Claro: UNESP, 2001, p. 97-137. Disponível em: http://homepage.mac.com/gilbertocorso/textos/Geo\%20e\%20Urbanismo.PDF. Acesso em: 02 maio 2012.

SANTOS, Elisabete; PINHO, José A. G. de; MORAES, Luiz R. S.; FISCHER, Tânia. O Caminho das Águas em Salvador: Bacias Hidrográficas, Bairros e Fontes. Salvador: CIAGS/UFBA; SEMA, 2010.

SANTOS, R. F. (organizadora). MINISTÉRIO DO MEIO AMBIENTE. Vulnerabilidade Ambiental - Desastres Naturais ou Fenômenos Induzido - Brasília: MMA, 2007. 192 p.

SILVA, Jorge Xavier da e ZAIDAN, Ricardo Tavares. (Orgs.) Geoprocessamento e analise ambiental: aplicações. Rio de Janeiro: Bertrand, Brasil, $4^{\circ}$ ed. 2004. 
Artigo recebido para publicação em jan/14

Artigo aceito para publicação em maio/14

Geo UERJ. Rio de Janeiro - Ano 16, no ${ }^{\circ}$.25, v. 1, $1^{\circ}$ semestre de 2014, pp.138-160 ISSN: 1415-7543 E-ISSN: 1981-9021

http://www.e-publicacoes.uerj.br/index.php/geouerj 